\title{
The Resource-Based Perspective An Assessment and Diagnosis of Problems
}

\author{
Foss, Nicolai J.
}

Document Version

Final published version

Publication date:

1997

\section{License}

CC BY-NC-ND

Citation for published version (APA):

Foss, N. J. (1997). The Resource-Based Perspective: An Assessment and Diagnosis of Problems. DRUID -

Danish Research Unit for Industrial Dynamics. DRUID Working Paper No. 97-1

Link to publication in CBS Research Portal

\section{General rights}

Copyright and moral rights for the publications made accessible in the public portal are retained by the authors and/or other copyright owners and it is a condition of accessing publications that users recognise and abide by the legal requirements associated with these rights.

Take down policy

If you believe that this document breaches copyright please contact us (research.lib@cbs.dk) providing details, and we will remove access to the work immediately and investigate your claim. 


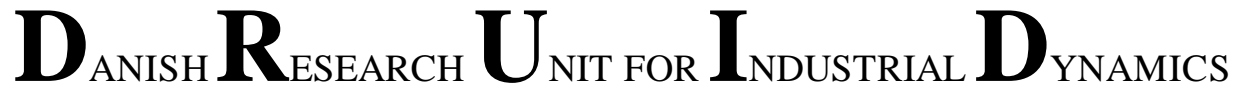

DRUID Working Paper No. 97-1

The Resource-Based Perspective:

An Assessment and Diagnosis of Problems

by

Nicolai J. Foss

January 1997 


\title{
The Resource-Based Perspective: \\ An Assessment and Diagnosis of Problems
}

\author{
by \\ Nicolai J. Foss \\ Department of Industrial Economics and Strategy \\ Copenhagen Business School \\ Nansensgade 19,6 \\ 1366 Copenhagen $\mathrm{K}$ \\ Denmark \\ Phone +45 38152562 \\ Fax +453815 2540 \\ E-mailESNJF@cbs.dk
}

\begin{abstract}
The resource-based approach to strategy, which reaches back to the contributions of Penrose, Selznick and Chandler, has gradually become the dominant perspective in strategy (content) research, arguably because it combines realism with relative rigour. The present paper presents the main themes of the contemporary version of the resource-based perspective (Wernerfelt, Rumelt, Barney....) and diagnoses a number of problems, such as the lack of a clear terminology, unclarity as to what really is the unit of analysis, the role of the environment, and the seemingly different versions that exist of the perspective. The perhaps deepest problem, however, is the lack of theorizing with respect to the creation of new resources, which tends to give the perspective a retrospective character and makes its application to managerial practice. It is suggested that resource-based scholars may draw upon work relating to real options, complementarities and organizational learning if they wish to remedy this deficiency.
\end{abstract}

\section{Keywords}

Organizational learning strategy

\section{JEL}

D21, D81, D23 


\section{Contents}

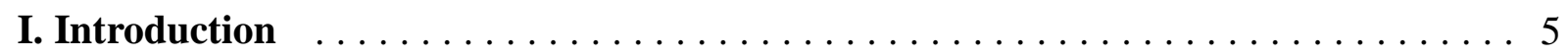

II. Main Themes of the Resource-Based Perspective $\ldots \ldots \ldots \ldots \ldots \ldots \ldots$

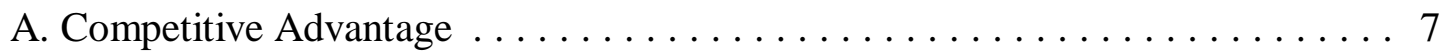

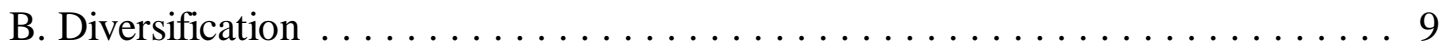

C. Why the Emergence of the Resource-Based Approach? . . . . . . . . . . . . 9

III. Problems and Weaknesses in the Resource-Based Perspective $\ldots \ldots \ldots \ldots \ldots \ldots 11$

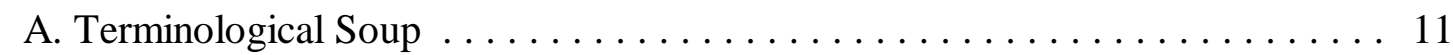

B. Different Versions of the Resource-Based Approach . . . . . . . . . . . . . 12

C. The 'Unfolding Process' of Firm Development $\ldots \ldots \ldots \ldots \ldots \ldots . \ldots \ldots$

D. Firm Development and the Resource-Based Perspective $\ldots \ldots \ldots \ldots \ldots$

E. The Lack of a Model of the Endogenous Creation of New Resources . . . . . 17

F. Equilibrium, Statics and Dynamics $\ldots \ldots \ldots \ldots \ldots \ldots \ldots \ldots \ldots$

G. What Is The Unit of Analysis? . . . . . . . . . . . . . . . . . . . . . . 19

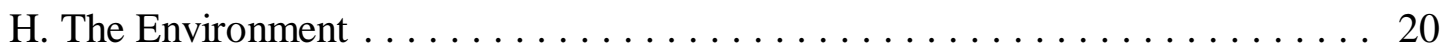

I. Testing and Measuring the RBP $\ldots \ldots \ldots \ldots \ldots \ldots \ldots \ldots \ldots \ldots \ldots \ldots \ldots$

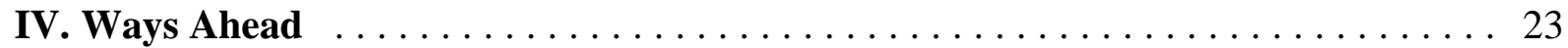

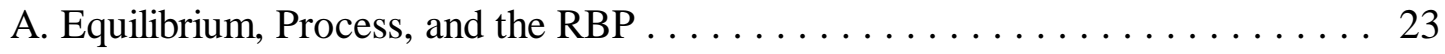

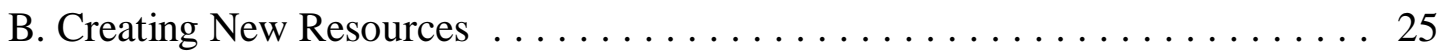

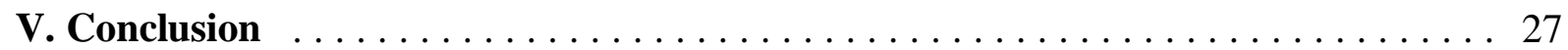

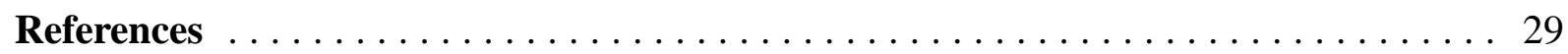





\section{Introduction ${ }^{1}$}

Arguably, firms are now increasingly prone to begin the strategy process by asking questions such as, 'Which are our central resources?', 'How can we augment and leverage our critical capabilities?', 'Is it desirable to try and build a new competence within this technical area?', etc. This is different, both in substance and focus, from such earlier and broad(er) questions as, 'What is our corporate mission?' or 'What businesses are we in?'.

Much of this reorientation in the way that the practical strategy-making process is carried out is undoubtedly due to the breakthrough in academic as well as practical strategy thinking of what is often referred to as 'the resource-based perspective' (henceforth, 'the RBP'). This perspective reaches long back in the (admittedly, brief) history of strategy, counting the classic contributions of Philip Selznick (1957), Edith Penrose (1959), and Alfred Chandler (1962) among the precursors.

In its modern manifestation, the resource-based approach may conveniently -- if admittedly somewhat arbitrarily -- be dated to the year 1984. This is the year of publication of two seminal articles, namely Birger Wernerfelt's 'A Resource-Based View of the Firm', and Richard P. Rumelt's 'Towards a Strategic Theory of the Firm'. These papers were quickly followed by a spate of important work, by such writers as Jay Barney, Cynthia Montgomery (the crucial contributions are reprinted in Foss, 1997), and the last decade is difficult to characterize as anything else than a wildfire of interest in resources, capabilities, competences, etc.

Thus, in little more than a decade, the RBP has emerged as the perhaps dominant contemporary approach to strategy. All the major academic strategy journals and also the more popular business periodicals regularly feature articles written from a resource-based perspective. A few resource-based strategy textbooks have appeared (Grant, 1991; Kay, 1993). In the business press, concepts such as 'resources', 'capabilities' and 'competences' are everywhere. In fact, what may be the perhaps ultimate litmus test of the general acceptance of the overall ideas of the resource-based perspective, the weekly, The Economist -- known for its acerbic comments on strategy thinking -- is now routinely employing resource-based concepts such as 'core competences'. In fact, the boom shows no sign of petering out, and a stock-taking and evaluation may therefore be considered premature.

Nevertheless, the ten-or-so years of existence of the RBP is a long period in the context of the strategy field, and the RBP is on such relatively firm grounds that I shall venture an assessment. The primary purpose of this assessment is to clear the ground for a discussion of what I feel are some pressing problems that threaten the coherence of the RBP. There are many good reasons for the success of the RBP; however, there may be reason to hold your breath and curb

\footnotetext{
1 This paper draws on the introductory and concluding chapter to Foss (1997).
} 
enthusiasm somewhat. There is agreement on important basic assumptions and insights, to be sure. And there has also been a certain cumulative theory development; for example, there has been a gradual refinement in the understanding of the conditions that resources must meet in order to yield rent.

However, there are also many unsolved problems and issues in need of clarification. Most conspicuously, perhaps, there is a considerable amount of terminological soup, with various resource-based theorists using concepts such as 'resources', 'competences', 'capabilities', 'assets', etc. for what is often essentially the same thing(s). Such problems may be overcome as certain terminological standards gradually become dominant in the community of resource-based theorists. But there are also deeper issues in need of clarification and potentially conflicting insights -- issues of which terminological confusion is merely a reflection. More specifically, I shall suggest that there is a number of unresolved problems with respect to issues such as 1) equilibrium vs disequilibrium, 2) the unit of analysis, 3) the role of the environment, etc. Because these issues are unresolved, the RBP is far from homogenous and, as I shall argue, actually exists in at least two versions, one stark, "formal" and explicitly drawing on economics, the other process-oriented and informal.

All this is really an indication of an even deeper difficulty, namely that there is little clarity and agreement as to how one actually goes on developing resource-based theories. How should it be done? On which disciplines should we primarily draw? Should economics still be a dominant source of inspiration or are there dangers associated with relying too much on economics? What are the relevant standards of excellence for resource-based research? What are the relevant benchmarks for theoretical development? Etc. In short, the perhaps deepest problem with the RBP is that there is no shared heuristics, in the sense of a "cookery-book" that details how resourcebased theories should be made. 


\section{Main Themes of the Resource-Based Perspective}

There are two main research themes in the RBP. The first concerns the analysis of the conditions for sustained competitive advantage, while the second essentially is diversification studies. Although these themes cannot be completely separated ${ }^{2}$, I shall nevertheless do this, first, because RBP theorists themselves treat the themes as separable (e.g., Peteraf, 1993), and, second, because it for expository reasons is convenient to do so. I shall also present a brief historical analysis of why the RBP emerged at the time it did; or, more precisely, why the time was ripe for its emergence. In other words, having presented the strengths of the approach in section A and B, section $\mathrm{C}$ describes the intellectual environment to which these strengths were deployed.

\section{A. Competitive Advantage}

The resource-based analysis of (sustained) competitive advantages begins from two basic empirical generalizations:

- There are systematic differences across firms in the extent to which they control resources that are necessary for implementing strategies.

- $\quad$ These differences are relatively stable.

The basic structure of the RBP emerges when these two generalizations are combined with fundamental assumptions that are to a large extent derived from economics. Among these assumptions are:

- Differences in firms' resource endowments cause performance differences.

- $\quad$ Firms seek to increase (if not necessarily maximize) their economic performance.

The overall managerial implication is that firms may secure a strong performance by building or otherwise acquiring certain endowments of resources. More generally, the overall objective that informs the RBP is to account for the creation, maintenance and renewal of competitive advantage in terms of the resource side of firms. More specifically, one is interested in linking the explanation of competitive advantage, and the dynamics of competitive advantages, to the characteristics of resources, and how these characteristics change over time.

\footnotetext{
2 For example, since the possibilities of obtaining competitive advantage in a market influences the decision whether the firm should enter or not). Moreover, as Montgomery and Wernerfelt (1988) clarify, diversification may be an important means to better exploit rent-yielding resources that are for some reason in excess.
} 
One may safely infer from this that the RBP is prone to asking fundamental questions -arguably, the fundamental questions. Arguably, this is another important reason for the recent success of the RBP: it is only by clarifying foundations and asking the truly fundamental questions that a sound theory of strategy can be built. Economics has played a key role here, since basic economic tools have allowed strategy researchers to pose and answer such fundamental questions in a more satisfactory way. Basic economics tells us that valuable resources that are in short supply relative to demand, and are therefore rare, may yield a distinct return that is caused to the resource being both valuable and rare. This return is called a rent. When for some reason it is impossible or prohibitively costly to imitate the resource, or substitute with another resource that can perform the same tasks, the rent from the resource may be long-lived. Basically, the resourcebased conception of competitive advantage is based on this analysis (which is undertaken in more detail in Barney, 1991).

The perhaps most systematic exposition of a resource-based perspective on the conditions for sustained competitive advantage is Peteraf's 1993 article, 'The Cornerstones of Competitive Advantage'. The 'cornerstones' in question refer to the insights that for resources to yield a sustained competitive advantage, they should meet four basic criteria:

- Heterogeneity -- i.e., in lieu of efficiency differences across resources, there cannot be any differences in the rents firm earn (in fact, there cannot be any rents at all). This indicates that resource heterogeneity, leading to efficiency differences and therefore rents, is a basic necessary condition for competitive advantage. An alternative formulation -- put forward by Jay Barney (1991) -- is that with homogenous resources, all firms can implement the same strategies; hence, no firm can differentiate itself from other firms, and nobody will have a competitive advantage.

- Ex ante limits to competition -- i.e., resources have to be acquired at a price below their discounted net present value in order to yield rents. Otherwise future rents will be fully absorbed in the price paid for the resource (Demsetz, 1973; Barney, 1986; Rumelt, 1987).

- Ex post limits to competition -- i.e., it should be difficult or impossible for competitors to imitate or substitute rent-yielding resources. As Ingemar Dierickx and Karel Cool (1989) clarify, there are a number of mechanisms at work that often makes it hard for competitors to copy the sources of competitive advantage of a successful firm. For example, there may be 'causal ambiguity', which means that competitors confront difficulties ascertaining precisely how a bundle of resource contributes to success.

- Imperfect mobility -- i.e., the resource should be relatively specific to the firm. Otherwise, the superior bargaining position that is obtained from not being tied to a firm can be utilized by the resource (or the resource's owner) to appropriate the rent (or, at least a large portion of the rent) that the resource helps create. In other words, the key question to ask here 
is, Who captures value from the resource, and how may the firm capture more value from the resource?

\section{B. Diversification}

If the inquiry into the conditions for sustained competitive advantage defines the one major research theme of the RBP, diversification studies surely constitute the other main theme. Although the basic story is much refined now, this is in itself no novel point, as firm growth through diversification was the subject of Penrose (1959), and she essentially laid the foundations for the resource-based analysis of this issue. What is new, however, is 1) the point that diversification may in turn help building new resources, as Costantinos Markides and Peter Williamson (1994) argue, 2) the realization that it is necessary to bring transaction costs into the story (Teece, 1980), and 3) the more rigorous form the argument has now taken.

Diversification studies may arguably be where the resource-based approach has had the greatest impact. The commonly accepted theory of diversification is roughly the resource-based theory. The basic story is the following one: firms gradually accumulate excess resources as a (non-intended) consequence of their normal operations. Tasks become routinized and this releases human resources, such as managerial resources; some physical resources are indivisible, which means that may not be fully exploited in their present use; etc. In principle, these resources could be traded over markets; however, the presence of transaction costs -- that is, the costs of actually making the exchanges -- will often hinder trading excess resources. As Teece (1980) clarifies, this is particularly likely to be the case if the resources in question are knowledge resources. An important implication of the theory is that firms earn decreasing average rents as they diversify more widely (Montgomery and Wernerfelt, 1988).

\section{Why the Emergence of the Resource-Based Approach?}

The emergence of the RBP can only understood on the background of what went on before its emergence (Collis and Montgomery, 1995). Part of the background is the set-back in popularity and respect that strategy suffered at the end of the 1970s. This was both a matter of strategic planning tools not being able to deliver what was expected from them and a result of critique of some of the important premises of the strategy enterprise. Thus, during the turmoil of the 1970s, firms had to learn the hard way that what was then called 'long-range planning' and somewhat less ambitiously, 'strategic planning', did not lead to the necessary adaptiveness or even survival. Fundamental critique of the epistemic presuppositions -- in fact, pretenses -- of the planning school, and also of its unrealistically optimistic view of strategy implementation, raised by the likes of Henry Mintzberg and James Brian Quinn, similarly did much to undermine the heavily 
rationalistic planning ideal ${ }^{3}$. All this meant that earlier hubris had to give way to a new pessimism. In the place of ambitious long-range planning, scenarios, attempts to grab market share at virtually any price, ride the experience curve, etc., came a much more introverted -- and also more timid -tendency, where (roughly) the focus shifted from the corporate and even business strategy level to the functional level.

The success of such practices as Total Quality Management, Business Process Reengineering, the learning organization, etc. are relatively recent manifestations of the more introverted stance. In its own way, Thomas Peters and Robert Waterman's In Search of Excellence (1982) also belong to this current, as does the general interest in corporate culture which this book, among others, inspired. The net effect of the more introverted stance was arguably an increasing emphasis on identifying, and wherever possible, extending, the strengths of individual firms.

What is important in the present connection, the more introverted stance probably also helped foster and sustain the basic resource-based idea that firms are essentially different and that the analysis of strategy and competitive advantage has to begin from this fact, rather than from the analysis of more aggregate competitive forces (e.g., in the industry). This is clear from inspecting the important strategy contributions from the period (Porter, 1980, being the exception). For example, there is Caves (1980) in which strategy is explicitly seen as the quest for efficiency rents; Quinn (1980) where strategy is defined as a means of allocating resources to a unique posture; Hofer and Schendel (1979) where the importance of competences is stressed; etc. There can be little doubt that the increased interest in the strengths of individual firms that began in the aftermath of the collapse of strategic planning models helped pave the ground for the RBP. 


\section{Problems and Weaknesses in the Resource-Based Perspective}

While the previous section mainly concentrated on the strengths of the RBP, the purpose of the present section is to undertake a more extended analysis of the problems and weaknesses that characterize the perspective.

\section{A. Terminological Soup}

One strong indication that the RBP is an emerging perspective is the absence of a clear and shared terminology. This is perhaps most conspicuously seen with respect to the terminology that is used for characterizing the key strengths of firms. According to many authors, these strengths are 'resources'. In his 1984 article, Birger Wernerfelt defines resources as 'anything which could be thought of as a strength or weakness of a given firm'. Jay Barney (1991), on the other hand, reserves the term 'resources' for virtually anything '...that enables the firm to conceive of and implement strategies that improve its efficiency and effectiveness' (p.101). C.K. Prahalad and Gary Hamel, in their enormously successful 1990 Harvard Business Review article, 'The Core Competence of The Corporation', prefer instead to talk about what in Wernerfelt and Barney's terminology is a specific type of resource, namely 'core competence'. They take this to be '...the collective learning of the organization, especially how to coordinate diverse production skills and integrate multiple streams of technology'.

There may be different rationales behind the introduction of concepts such as 'capabilities' or 'competencies', particularly when they are seen as different from 'resources'. One such rationale may be that it captures the distinction between stocks, for example, resources, and flows, that it, the services that may be obtained from resources. Another reason is that some resource-based theorists apparently feel that it is desirable to make distinctions between assets based on their ability to contribute to competitive advantage. Clearly, not all assets are significant in these terms. Those who use concepts such as compentecies or capabilities normally feel that it is knowledge assets that are the most likely candidates for bringing firms sustained competitive advantage.

However, while entirely plausible, this may at most be a matter of empirical generalization, not of strict logic. For although intuition would support the view that knowledge assets are on the whole the most important ones, there are in fact numerous examples of physical assets bringing firms sustained competitive advantage. For example, telephone and cable companies are certainly advantageously positioned in the emerging multimedia industry because of their possession of nets of transmission, that is, of certain physical resources (Collis \& Montgomery, 1995: 119). This suggests that it is more sensible to begin by developing insight into which criteria any asset should meet in order to yield sustained competitive advantage, rather than determine and settle on a given asset category on the basis of casual empiricism or arbitrary choice. In fact, this is exactly what resource-based strategy scholars have done (e.g., Barney, 
1991; Peteraf, 1993), and this is also where economics enters the scene.

\section{B. Different Versions of the Resource-Based Approach}

Uhe overall objective that informs the RBP, it has been argued, is to account for the creation, maintenance and renewal of competitive advantage in terms of the characteristics and dynamics of the internal resources of firms. That is an ambitious and demanding task. However, if one thinks of the RBP as constituting one integrated perspective on strategic management, one may argue that it does meet the overall objective reasonably well.

However, the problem is that the RBP is not yet 'one integrated perspective'. It is a set of contributions published over the last approximately 15 years (plus some important precursors to these contributions) that share a number of basic themes. But, apart from that, the contributions that may be seen as constituting the RBP are undeniably quite heterogeneous in terms of, for example, style (written for managers or written for academics, formalization, rigor, etc.) and in terms of which disciplines they draw on (economics, sociology, psychology, decision theory). For example, it is hard to see what are the shared ideas in Prahalad and Hamel's (1990) 'The Core Competence of the Corporation' and Lippman and Rumelt's highly formal 1982 paper on 'Uncertain Imitability: An Analysis of Interfirm Differences Under Competition'. However, they are both usually seen as important contributions to the RBP.

The distinction between the two versions of the RBP is primarily one of whether dynamic factors are included in theorizing. While dynamics (innovation, organizational learning, resourceaccumulation, competence-building, the development of mental models of the management team, etc.) comes first in recent work on core competences and dynamic capabilities, statics comes first in the traditional resource-based approach. That is, in the traditional resource-based approach one begins by clarifying and examining the conditions that must obtain in order for resources to yield rents in equilibrium. This is the procedure followed in, for example, Barney (1986) or Peteraf (1993). Here, issues relating to processes of accumulation of resources enter subsequently, or are simply suppressed.

One may interpret this branching in different ways. In one (plausible) reading, the two branches of the RBP are not in conflict. They are different, but complementary (Mahoney, 1995), the one being preoccupied with strategy content research, the other one with strategy process research. The task ahead is to integrate more fully these two ways of framing the RBP. Indeed, one may argue, with Spender (1992), that what he calls 'resource-learning' -- human resources learning about the services of other resources -- is the RBP's key to advancement (cf. Mahoney, 1995: 96). That would bring us back to Penrose once more, for her story of firm growth is very much such a theory of resource-learning. 


\section{The 'Unfolding Process' of Firm Development}

Edith Penrose (1959: 1) referred to the development of firms as an 'unfolding' process -- a process that is based on the endogenous change of the firm's resources and the services these resources yield. Hers is certainly an evolutionary theory in a broad sense of the word. Since the specifics of resource-accumulation processes are different across firms, firms will end up holding different bundles of resources and services and will therefore articulate different strategies based on these resources and services. This, we note in passing, is a quite revolutionary insight, because economists have normally assumed that firms differ either because they come equipped from their 'birth' with different endowments of resources (e.g., different endowments of entrepreneurial talent, cf. Lucas, 1978) or because they are placed in different industries. Endogenous change through managerial discretion has not normally played a role in economic analysis, because economists have traditionally worked with an extremely stylized view of the firm and because equilibrium methodology and the comparative static method of analysis have hindered the development of theories of endogenous change in general.

Now, what precisely is meant by saying that the development of firms describes 'an unfolding process'? An old idea is to argue that firms go through a life-cycle much like the lifecycle that biological organisms go through -- an idea that was strongly criticized by Penrose (1952). However, it may not be entirely unreasonable to assume that there is a sort of overall development that takes place in identifiable stages to the history of most firms. Indeed, in a rough way, such an argument lies behind such claims that diversification naturally follows growth, that efficiency considerations normally dictate that diversified companies have M-form structures, that decentralized M-form corporations in turn confronts a significant risk of losing innovation ability, etc. I here discuss a modern stage theory of firm development, one that allows to put in perspective some of the strengths and weakness of the RBP.

Hogarth, Michaud, Doz and Van der Heyden (1991) develop a four stage framework for analyzing firm activities, specifically in order to gain insight into how different types of activities influenced long-term viability. Thus, their aim is to combine the analysis of firm growth and change with the analysis of sustained competitive advantage, to combine, in other words, process issues with content issues. Hogarth et al. argue that the activities of firms could be described in terms of the stages of:

- 1. Privileged access. Activities in this stage result from some privileged access to primary resources and/or markets.

- 2. Transformation. Firms transform resources into products, for example, by superior processes inherited from the past. However, firms at this stage lack ability to change processes. In the longer run, these processes will become imitable. Thus, long-run above- 
normal returns cannot be obtained from stage 2 processes.

- 3. Leverage. At this stage, firms are capable of renewing their processes of transformation (their productive capabilities), and thereby hinder competitive imitation and substitution (for at least some time). This means that they can obtain above-normal returns for long periods of time. However, stage 3 activities become stage 2 activities as imitators catch up.

- 4. Regeneration. At this final stage firms are not only capable of changing their methods of transformation, but also their ways of searching for new methods of transformation (their dynamic capabilities). In other words, stage 4 activities operate on stage 3 activities, as it were.

There is no presumption in this stage theory that all firms must by some inevitable logic pass through all stages or must pass through the stages one at a time. Many firms do not reach stage 4 or even stage 3 , and most firms contain activities that are at more than one stage. In fact, the stage framework is more of a normative nature than of a descriptive nature: it is a theoretical attempt to examine the conditions for sustained competitive advantage in terms of development possibilities. Thus, the bottomline of Hogarth et al.'s paper essentially is that in order to secure sustained competitive advantage, firms have to control certain resources, notably a core-group of managers and dynamic capabilities or core competences. This basically comes to the same thing as the argument that ultimately learning is the only sustainable source of competitive advantage (Williams, 1992).

In the context of understanding the strengths and weaknesses of the RBP, the Hogarth et al. framework has the clear advantage that its sequential mode of analysis allows an identification of precisely where -- that is, with respect to which kinds of firm activities -- the RBP suffer from weaknesses and where it possesses strengths. Moreover, the framework points to the need of more fully integrating process issues -- such as organizational learning -- with content issues, such as the analysis of sustained competitive advantage (Mahoney, 1995).

Thus, we can rather safely say that the resource-based approach is strong on aspects of the analysis of stage 1 activities ('Privileged access'). In resource-based terminology, privileged access means to control valuable and rare resources. More specifically, Jay Barney's factor market analysis (1986) clearly belongs here with its point that a necessary condition for a resource to yield rent to its owner is that the resource in question is acquired at a price that is below the expected 
value of the resource. ${ }^{4}$

Now, privileged access says nothing about how the resources to which one has a privileged access are actually employed in production. Stage 2 activities ('Transformation') refer to processes of production that may be unique in the short run, and thus give rise to a competitive advantage. However, stage 2 firms have not yet learned how to change and adapt processes -- they only possess what may be called 'static capabilities'. As a result, competitive advantage can only be temporary. Clearly, the resource-based analysis of the competitive dynamics of imitation and substitution relates to the understanding of the implications of stage 2 activities for competitive advantage. In general, basic microeconomics helps understanding much of the content and dynamics of stage 2 activities.

Stage 3 ('Leverage') activities involve changes in established processes of production (including routines and capabilities/competences), where these changes may help the firm pursue generic strategies, such as cost or quality leadership, or change its information systems, organization design, etc. In other words, stage 3 activities are a matter of innovations in products, processes or organization.

What characterizes stage 4 ('Regeneration') firms is their ability to achieve sustained competitive advantage by means of an ability to generate a continuous stream of stage 3 activities. Whereas stage 3 activities involve the ability to invent and exploit new products, processes, organizational forms, etc., stage 4 activities involve the ability to invent and/or absorb new ways of accomplishing this. Thus, stage 4 firms would seem to 'hypercompetitive' in the sense of D'Aveni (1994) and their characteristic capabilities correspond to what Teece, Pisano and Shuen (1995) call 'dynamic capabilities'.

More generally, one may conjecture that activities at the four different stages of development are supported by different types of resources. Thus, resources that support the relatively trivial (in terms of the analysis of competitive advantage) stage 2 activities may be rather different from the type of resources that support stage 3 or 4 activities. Whereas important stage 2 resources may be physical resources, it is plausible to presume that important stage 3 or 4 resources are organizational resources, such as learning capabilities. Moreover, there is a presumption that the latter type of resources may better satisfy the basic resource-based criteria for being rare, valuable, costly to imitate, etc. This is so because they are -- almost per definition -more likely to be strongly firm-specific, (therefore) hard to trade, socially complex, characterized by causal ambiguity, etc. -- all following from their being internally accumulated through history-

Another example is Foss and Eriksen's (1995) concept of 'industry capabilities'. These are resources that are shared by incumbents but are not available to outsiders, such as trust relations, specific ways of diffusing and sharing technological knowledge, etc. Foss and Eriksen argue that such shared resources may yield rents to incumbents, for example, firms in industrial districts. This clearly also links up with Michael Porter's (1990) recent analysis of national 'diamonds' and how these are defined by, among other things, the resource endowments of the nation. 
bound, path-dependent processes of change. Thus, in this way the analysis of firm development, the analysis of resource categories, and the analysis of sustainability of competitive advantage join hands.

\section{Firm Development and the Resource-Based Perspective}

As already stated, the Hogarth et al. framework is useful in our context because it points to some weak points in the RBP -- such as the lack of integration of the analysis of firm growth and change with the analysis of sustained competitive advantage --, and more generally because it allows us to isolate where the RBP is strong and where it isn't. Moreover, it also provides a way of identifying and illustrating some of the differences among the various approaches and contributions that together constitute the RBP.

With respect to the strengts/weaknesses issue, it has already been noted that the RBP is strong with respect to the analysis of the stage 1 activities of privileged access and that it has interesting things to say about the stage 2 activities of transformation and their competitive implications. The resource-based analysis of stage 3 activities ('Leverage') is represented, for example, by Dierickx and Cool's analysis in 'Asset Stock Accumulation and the Sustainability of Competitive Advantage' (1989), which is one of the first and still most important attempts to take the RBP in a more dynamic direction. Dierickx and Cool's concepts of, for example, asset-mass efficiencies, asset stock interconnectedness, etc, -- as well as their overall stock-flow approach -brought the RBP much further with respect to placing the analysis of sustained competitive advantage in a dynamic framework. But much work clearly remains to be done here.

It is clearly with respect to the analysis of stage 4 activities ('Regeneration') -- the most 'dynamic' stage of the Hogarth et al. framework -- that the RBP is weakest. Assuredly, regeneration activities have been a dominant issue in the many contributions that have been inspired by Prahalad and Hamel (1990) Indeed, their understanding of core competences as the '...collective learning in the organization, especially how to coordinate diverse production skills and integrate multiple streams of technology', and involving the ability to 'spawn new unanticipated products' seems to be one way of approaching the nature of the competences/capabilities that underlie stage 4 activities. However, these contributions are recent, few in number and often highly informal. Here, too, much more work needs to be done.

To sum up, viewing the RBP through the lens provided by the Hogart et al. stage framework reveals a general difficulty of handling the more dynamic issues of resource creation. More formal contributions to the RBP largely neglect these issues, while less formal contributions (such as Prahalad and Hamel's contributions) are admittedly concerned with these, but reason in terms of such broad and sometimes diffuse terms that their real contribution to the advancement of the RBP is questionable. 


\section{E. The Lack of a Model of the Endogenous Creation of New Resources}

The underlying problem in this context is that there is no clear conceptual model of the endogenous creation of new resources to be found in the RBP. This lack accounts for the inability for the RBP to really come to grips with what was in the Hogart et al. framework called stage 3 and 4 activities. And it explains the co-existence in resource-based strategy theorizing of two widely different styles of discourse, one stark, rigorous and static; the other one loose, informal and oriented toward dynamics.

One may argue that it is in the nature of the RBP that there is no model of endogenous creation of resources, for it would imply 1) generalizing about the unique (namely resources), and 2) that there is a 'rule for riches' (which there isn't). But this argument would be wrong, for in a limited sense the RBP itself generalizes about the unique (e.g., resources have to rare, valuable, non-imitable, etc. in order to yield rents), and a theory about the creation of resources does not necessarily imply a rule for riches. In fact, a few contributions are clearly reaching for a model of endogenous resource-creation, notably Dierickx and Cool (1989) and Wernerfelt (1984). But again, these are first beginnings, albeit important ones.

Before speculating on how this important weakness may be remedied, let us consider the deeper reasons why the RBP suffers from such a weakness. The above observations point to more fundamental discussions that are well-known to economists and also to strategy theorist influenced by economics; namely the issue of the role of equilibrium in work in strategy research (e.g., whether equilibrium models inherently introduce a static bias). Numerous economists have pointed out that equilibrium assumptions and the restrictive behavioral assumptions that normally accompany equilibrium models (such as admitting only maximizing rationality) will seriously impede the development of models of endogenous change (e.g., Nelson and Winter, 1982).

Relatedly, one may also argue that one reason why there is not one clear-cut resourcebased approach, but rather a somewhat heterogeneous literature with a few shared organizing themes, is that economics (and equilibrium models) is relied upon to varying extent by different contributors to the approach. For example, Prahalad and Hamel at most rely on economics in a background way, while contributors such as Wernerfelt, Montgomery, Barney and others quite explicitly rely on economics. Arguably, this influences not only the form of the contributions (i.e., whether economic concepts are actually used, the degree of abstraction and rigor, whether mathematical models are used, etc.), but also the content. Those who are skeptic with respect to the economic turn in strategy thinking usually is so because they hold the position that relying too much on economics (particularly neoclassical economics) cut off some phenomena. Thus, they would argue economics introduces a static bias to strategy thinking, this means that it becomes different to approach and understand dynamic phenomena such as innovation and learning. They may have a point. Let us take a closer look at the issues. 


\section{F. Equilibrium, Statics and Dynamics}

The concept of equilibrium is, of course, a cornerstone in most economic thinking. However, the concept is not entirely unambiguous. There are several different and not necessarily compatible meanings of equilibrium. In its simplest version, equilibrium simply means equality between supply and demand at a given point of time. In this version, the concept is rather uncontroversial: most economists and strategy scholars would accept that product and factor markets are often in equilibrium in this sense, and that a tendency towards such an equilibrium can be relied upon (cf. Kirzner, 1973). Controversy may begin when equilibrium is given an intertemporal dimension -for example, equilibrium as consistency of plans -- and an informational interpretation, for example, equilibrium as obtaining when prices reflect all public and private information. These constructs are much more restrictive than simple supply-demand equilibrium.

It is clearly the case that equilibrium assumptions play a key role in many contributions to the RBP. This is the case in Peteraf (1993), in which the concept of Ricardian rent is developed using efficiency differences across firms under competitive equilibrium as a benchmark. And it is also the case in Barney (1986), in which the finance concepts of strong and weak efficiency are (implicitly) used to elucidate the reasoning behind the concepts of perfect factor markets and factor market imperfections. Indeed, the very concept of sustained competitive advantage is often defined in equilibrium terms: it is that advantage which lasts after all attempts at imitation have ceased. This has the implication, unfortunately, that sustained competitive advantage has no meaning outside equilibrium, and that the concept is hard to operationalize.

Now, equilibrium theories may take different forms. It is one thing to say that all phenomena should be represented as if in equilibrium -- what may be called 'hard' neoclassical equilibrium economics. And it is quite another thing to admit equilibrium as a legitimate tool of analysis, for example, as a state that real-world markets are constantly tending toward (but perhaps not reaching) -- what may be called a 'weaker' or more 'Austrian' type of equilibrium economics (Kirzner, 1973).

The RBP is not by necessity committed to the first kind of equilibrium theory; it is perfectly possible to cast the key resource-based ideas in terms of the 'weaker' type of equilibrium economics. Moreover, a tight connection between the understanding of competitive advantage and 'hard' equilibrium economics surely hinders understanding a number of real world phenomena. As a general matter, we are cut off from approaching the disequilibrium aspect of competitive advantage; for example, mainting competitive advantage through engaging in a stream of what was called 'stage 3' and 'stage 4' activities above. Learning and innovation activities involve per definition novelties in the sense of the acquisition or creation of novel knowledge -- and such novelties are hard to force into an equilibrium straitjacket.

Equilibrium models may be useful in connection with tracing the effects of the creation of new knowledge -- for example, the effects on factor prices of the creation and diffusion of new 
technical knowledge -- but they tell us next to nothing about the process of creation of new knowledge. Thus, one important reason why the RBP lacks a clear model of the endogenous creation of resources may simply be that (hard) equilibrium economics has been such an important force in the development of the RBP. Notice that this is not a call for abandoning the reliance on economics; it is rather a call for being open to other types of economics than standard neoclassical equilibrium economics, such as evolutionary economics (Nelson \& Winter, 1982) (more about this later).

\section{G. What Is The Unit of Analysis?}

The role of economics may also be relevant in another issue of at least potential disagreement within the RBP, namely what should be the relevant unit of analysis. The problem of finding the appropriate unit of analysis in the study of firms is a general one. For example, phenomena relating to firms may be approached using, in ascending order of aggregation, decisions and decision premises, transactions, contracts, activities, processes, routines, capabilities, strategic business units, core competences, even the firm itself as the relevant unit of analysis. Clearly, what one chooses to use depends on what one wishes to examine and illuminate. For example, if the objective is to examine a firm's relations to suppliers, contracts are likely to be the appropriate unit of analysis. However, if one aims at understanding the creation of a corporate technology base, the level of core competences may be the appropriate unit of analysis.

However, most contributions within the RBP take the individual resource as the relevant unit of analysis. For example, Peteraf's (1993) analysis clearly applies to the individual resource: it is isolated and evaluated in terms of heterogeneity, whether it was acquired at price below cost, etc. Arguably, this approach may owe something to the influence of economics on the RBP, because economics are often seen to promote a tendency to analytical atomism. On the substantial level, there may be dangers of taking the individual resource as the unit of analysis. Admittedly, this procedure may in some case be completely legitimate because the relevant resource is sufficiently well-defined and free-standing. An example may be a pharmaceutical firm that wishes to evaluate the rent-yielding potential of a new patent. But it may also lead analysis astray and result in wrong advice.

This is particularly so, when there are strong relations of complementarity and cospecialization among individual resources, so that it is not really the individual resources, but rather the way resources are clustered and how they interplay, that is important to competitive advantage. Arguably, it is this clustering and interplay that those contributors to the RBP who prefer to talk about 'capabilities' or 'competences' rather than 'resources' wish to emphasize. In terms of Dierickx and Cool's (1989) framework internally accumulated asset stocks often represent clustered resources (i.e., 'asset stock interconnectedness' effects) and individual resources are primarily important because they help maintain or build stocks of such clustered resources. 
The upshot of all this is that one should exercise much care when analyzing resources on an individual and free-standing basis, for example, asking whether the relevant resource is 'unique', 'rare', etc. It may often not be the uniqueness or rareness of the resource that matters, but rather its ability to fit into a system. This question of embeddedness lead into a broader embeddedness issue, namely the firm's embeddedness in its environment.

\section{H. The Environment}

It has been a commonplace in the debate in strategy on the RBP that it 'neglects the environment'. This is not entirely accurate, but it is not entirely wrong either. For example, Dierickx and Cool (1989) argue that '...product market positioning and unique resources work together to determine competitive advantage' (1989: 1510). And Wernerfelt (1984) argue much the same, pointing out that product market perspectives and the RBP '...should ultimately yield the same perspectives'. Thus, the environment is at least not completely neglected. Moreover, environmental analysis -the analysis of how to best position in a product-market -- and the RBP may be seen as at least complementary. Specifically, the Porter industry analysis approach would not seem to be opposed to the RBP.

In one form of this argument, the approaches are complementary for the simple reason that they have different domains of application: in the context of the SWOT framework, the domain of application of the RBP is the analysis of the strengths and weaknesses of firms, while the analysis of environmental threats and opportunities is the domain of, for example, the Porter industry analysis approach. Such an argument has been made quite explicitly by, for example, Barney (1991).

The argument provokes some comments, however. First, it is correct that the environment has not been treated in detail in the RBP. Second, it is probably to give in too much to say that the domain of application of the RBP is restricted to the firm and not to the environment. A resource-based approach may in fact be helpful in connection with analyzing environmental phenomena. For example, Schoemaker and Amit (1994) coined and analyzed the concept of 'strategic industry factors', which are industry-specific sets of resources that affect industry profitability. Dierickx and Cool (1989) noted that firms don't necessarily have to own resources in order to reap rents from exploiting them. For example, firms may benefit from positive externalities, as when a firm that sells skiing equipment benefits from being placed close to a popular ski-resort.

More generally, resource-based insights may further understanding of industry-level competitive dynamics. For example, the RBP may be helpful for understanding the nature of mobility and entry-barriers, since it directs attention to the resources that underlie these barriers. For example, it is not sufficient to know what is the minimum efficient scale in terms of produced units in an industry; an entrant also wish to have information about the resources that are 
necessary for efficiently producing at this scale of production. The RBP may also be helpful for understanding competitor expectations, since these expectations are partly formed on the basis of knowledge about competitors' resources. For example, the path-dependency that firm resources introduce constrains firms' possible competitive moves. Thus, applying the RBP better helps understanding the nature of competitive threats. In sum, the RBP may in fact add some more finegrained analysis to industry analysis based on industrial organization economics. There is at least a basis for fertile dialogue here.

\section{Testing and Measuring the RBP}

In a perceptive critique of the RBP, Michael Porter (1994) argued that

'[a]t its worst, the resource-based view is circular. Successful firms are successful because they have unique resources. They should nurture these resources to be successful. But what is a unique resource? What makes it valuable? Why was a firm able to create or acquire it? Why does the original owner or current holder of the resource not bid the value away? What allows a resource to retain its value in the future? There is once again a chain of causality that this literature is just beginning to unravel'

Because Porter's objection that the RBP may suffer from circular reasoning is purely logical, it will not do to dismiss this criticism with the argument that he attacks the RBP from a competing perspective. It has to be taken seriously. Elaine Mosakowski and Bill McKelvey (1995: 1-2) elaborated on Porter's charge of tautological reasoning:

The current state of the strategic management work on the resource-based view represents tautological reasoning of the sort that 1) rents are often used to define a firm's critical resources in that these resources are identified by comparing successful versus unsuccessful firms; and then 2) the question is asked whether critical resources generate rents, to which a resounding YES is heard'

Obviously, this methodology is unacceptable; for example, it makes the RBP completely unfalsifiable. But in principle there is also a way out, and this is to operationalize the key criteria that resources have to meet in order to yield long-lived rents. Thus, one has to construct proxy variables that correspond to, for example, Barney's (1991) argument that sustained competitive advantage hinges on whether resources are valuable, rare, and very costly to imitate and substitute. In principle, this can be done: for example, expert panels can be used for obtaining information about the cost of imitation, estimates of rareness may be obtained from simple counting of the resources possessed by competing firms, etc. These proxy variables can then be 
used as independent variables to examine how much they explain of returns, for example, of the dispersal of returns within a population of firms or of changes in returns as explained by changes in the characteristics of resources. 


\section{Ways Ahead}

Well-defined problems often suggest their own solutions, and the more so, the more well-defined and understood they are. And the above problems, to the extent that they are well-defined, may point to various remedies. So, let us take stock and recapitulate some of the main problems to which no ready answer was given in the above:

- The RBP has difficulties coming to grips with processes of creation of new resources.

- The RBP may be too much wedded to equilibrium methodology.

- There is a tendency to evaluate resources as individual and free-standing entities.

Admittedly these problems do not characterize all contributions to the RBP. For example, the more informal literature on core competences discusses processes of creation of resources, innovation, learning, etc., and it does not evaluate resources as individual and free-standing entities. However, this literature suffers from a certain looseness and imprecision, which is not only a matter of its more explicitly managerial orientation, but also a product of its attempt to grapple with complex and dynamic issues.

What the RBP needs, therefore, is more agreement that the dynamic issues that are featured in such contributions as Prahalad and Hamel (1990) are crucial, but should be approached in a more precise and analytical way. If this does not happen, there is a real danger that the RBP may split even more visibly into, first, a formal, stark, abstract branch strongly inspired by economics and gradually losing contact with the managerial reality, and, second, an increasingly loose and free-wheeling branch where almost anything goes on the analytical level. Whether this will happen or not may crucially depend on successfully approaching and solving some of the problems that were identified above. In the following, I shall briefly discuss some possible remedies to these problems.

\section{A. Equilibrium, Process, and the RBP}

There is no reason for resource-based theorists to completely abandon equilibrium ideas. As previously stated, equilibrium concepts are useful, both in an ex ante sense where they give us some understanding of the direction of the market process, and in an ex post sense where they help us organizing historical experience. Moreover, they may be helpful as benchmarks; for example, perfectly efficient markets rule out competitive advantages. But equilibrium concepts may also introduce a static bias and they may, if used in a too heavy-handed way, hinder understanding of 
process (disequilibrium) phenomena ${ }^{5}$. Intuitively, strategy is very much about exploiting and perhaps even initiating (á la Schumpeter) periods of disequilibrium, and we wish to theorize this aspect of strategy, too. In general, there is a need for bringing process issues more directly into the focus of resource-based theorists.

It is understandable that economics and particularly equilibrium economics has had such an influence on the RBP: it is not only that it becomes possible to understand more phenomena better -- it is also a matter of making heuristic progress (e.g., clearer concepts, mathematical RBP models (such as Wernerfelt, 1995)). Some resource-based theorists may fear that interest in process issues may sacrifice this heuristic progress, because process issues are notoriously more fuzzy and difficult to understand than equilibrium.

This does not necessarily have to happen. Specifically, theorizing disequilibrium phenomena does not mean that formalization is ruled out. In fact, there are now many formal models in evolutionary economics (beginning with Nelson and Winter, 1982). These models are not only about the market process, that is, the process of interaction of firms. They also address internal organization issues (see, e.g., Marengo, 1992).

More generally, evolutionary economics and the RBP are both characterized by emphasizing fundamental heterogeneity of firms as a necessary starting point for theorizing. There are many other important similarities between the two approaches (see Foss, Knudsen and Montgomery, 1995; Foss, 1996), and the RBP in particular may benefit from being infused with a dose of evolutionary economics. For example, evolutionary economists have cultivated an advanced understanding of the mechanisms of technological change -- insights that may both help develop a more refined resource-based analysis of the environment and help understanding the process of creation of new resources through innovation. Thus, one attractive way ahead for the RBP is to strike a closer intellectual strategic alliance with evolutionary theorists, most importantly because evolutionary economics adds a dynamic dimension and does so in a rather precise and formal way. However, there are also other types of recent work in economics and strategy research that may be helpful in the context of making the RBP more dynamic. These are considered in the following section.

\footnotetext{
Penrose (1959) explicitly rejected equilibrium theories of the firm, pointing out that 'The attainment of such a "state of rest" [i.e., equilibrium] is precluded by three significant obstacles: those arising from the familiar difficulties posed by the indivisibility of resources; those arising from the fact that the same resources can be used differently under different circumstances, and, in particular, in a specialized manner; and those arising because in the ordinary processes of operation an expansion new productive services are continually being created' (1959: 68).
} 


\section{B. Creating New Resources}

The argument here has been that an important shortcoming of the RBP is that there is no welldeveloped model of endogenous resource creation. Mostly, theorists analyze the end-states of previous processes of resource-creation (including processes of organizational learning). However, in order to account for the emergence and maintenance of the systematic heterogeneity among firms that is a basic premise of the RBP, it would seem to be necessary to develop some model(s) of endogenous change. At the present state of analysis, heterogeneity is simply asserted. However, there are different types of work in strategy thinking and economics that may help overcome this deficiency. For example, there is important contemporary work on:

-Real options (Sanchez, 1993).

- Path-dependency (Arthur, 1989).

- Organizational learning (Huber, 1989; Marengo, 1992).

- Complementarities (Milgrom and Roberts, 1995).

In the context of furthering the RBP, work on real options may be the most immediately useful contribution. In the theory of real options, one conceptualizes firms not as bundles of resources per se, but rather as portfolios of real options. In analogy with the finance notion of an options, firms are seen as having at any point of time a number of strategic options which they may exercise in their input (e.g., spot markets, alliances, long contracts, vertical integration, etc.) and output markets (e.g., different products, different designs, different marketing channels, etc.). The aim of strategy in this perspective becomes the acquisition of an optimal bundle of options where optimality is a matter of striking a balance between the costs of acquisition of options and the benefits these options may bring in terms of added flexibility.

A clear advantage of this work in relation to the furtherance of the RBP is that it is a step in the direction of a better understanding of the endogenous creation of resources. Thus, the creation of new resources may often be understood in option terms as a matter of creating new product options. In other words, firms' processes of resource creation may be seen as a matter of creating product options and then finding ways to defer and make contingent their acquisition of the resources they need to produce those products in the future (Sanchez, 1993: 269). Thus, the accumulation and/or acquisition of resources become contingent on managerial expectations and aspirations, and the real options perspective therefore goes some way towards furthering our understanding of the mechanisms underlying endogenous change in firms' stocks of resources.

On the other hand, the RBP may complement the options perspective by pointing out that 
new options are often -- and generally should be -- acquired in areas of competence that are 'close in' to the firm's existing area of competence. This is simply one consequence of the general resource-based emphasis on relatedness in investment projects such as diversification and the acquisition of options -- a view that is fundamentally, if implicitly, rooted in the connected notions of path-dependency, organizational learning, and complementarity.

Firms generally seem to learn more and better in learning domains that are not far away from existing learning domains. Among the reasons why this is so is that much of the relevant learning is essentially organizational in nature. One interpretation of 'organizational' here is that the learning in question is synergistic because of complementarities among individual learning processes $^{6}$. That is, these learning processes feed on each other, and it is this characteristic that makes the relevant learning genuinely organizational rather than individual. Moreover, learning implies sunk costs. As a result firms are strongly constrained in their abilities to change paths of development. On the theoretical level, such path-dependency effects help understanding persistent heterogeneity across firms, serve as predictors of the future process of accumulation of resources, and adds conceptual meat to the concept of 'relatedness' -- a concept that is important to the resource-based analysis of diversification. Most importantly, however, all the four concepts above help us adding a dynamic dimension to the RBP and they allow us to do this in a relatively rigorous way.

The economic concept of complementarity is that the returns from investing in an asset-stock varies positively with the height of other asset stocks. For example, the return from further investments in R\&D may be an increasing function of how much marketing knowledge is accumulated. 


\section{Conclusion}

Assuredly, any theoretical perspective carries with it an open horizon, as it were. A perspective or, more ambitiously, a paradigm, is first and foremost a box of tools that are used to attack problems of both a theoretical and practical nature. And we cannot -- as a purely logical matter -exactly know in advance how our perspective will fare with respect to future problem-solving. In this sense, therefore, a theoretical perspective will always imply uncertainty because it frames unsolved problems (Loasby, 1976).

That being said, however, the hallmark of a well-developed perspective is that the toolbox is internally consistent -- the theoretical concepts, tools and models should not be in conflict -and that there is 'a cookery book', that is to say, a set of agreed upon rules as to how one actually solves problems within the perspective. The problems that a well-developed perspective confronts are therefore more in the nature of problems of application and problems of how the perspective should be extended and modified under the impact of empirical reality than they are matters of problems of internal consistency and terminology.

The RBP is not a complete approach to strategy. It does not feature a distinct approach to analyzing the environment; it is concerned with the content rather than the process side of strategy; it has difficulties accounting for the process of creation of new resources; etc. Admittedly, these are all shortcomings, some more serious than others, some more remediable than others.

Perhaps, we should not expect overly much on behalf of an approach that in its modern manifestation has only been in existence for little more than a decade. Some modesty may be appropriate. Tensions and unsolved problems will stay with the RBP for a long time to come. What we can do, however, is to evaluate the RBP on what has so far accomplished and what it promises to deliver in the future. On balance, the impression that is one of considerable achievement: The RBP has rediscovered, revitalized and refined crucial, but somewhat neglected, ideas associated with older writers. It has brought increasing rigor and precision to the strategy field, without losing contact with practical reality. Perhaps most importantly, it has asked and with considerable success answered some of the basic questions of strategy in novel and stimulating ways. 


\section{References}

Andrews, Kenneth (1971), The Concept of Corporate Strategy, 1993 ed., Homewood: JamesIrwin.

Arthur, W. Brian (1989), 'Competing Technologies, Increasing Returns, and Lock-In by Historical Events,' Economic Journal, 99, 116-131.

Aveni, Richard (1994), Hypercompetition: Managing the Dynamics of Strategic Maneuvering, New York: Free Press.

Bain, Joe (1959), Industrial Organization, Wiley, New York.

Barney, Jay B. (1986), “Strategic Factor Markets”, Management Science 32: 1231-1241.

Barney, Jay. B. (1991), 'Firm Resources and Sustained Competitive Advantage', Journal of Management 17: 99-120.

Barney, Jay B. (1995), 'The Resource Based View: Evolution, Current Status, and Future', handout for a presentation, Third International Workshop on Competence-Based Competition, Ghent, Belgium, November, 1995.

Caves, Richard E. (1980), 'Industrial Organization, Corporate Structure, and Strategy', Journal of Economic Literature 18: 64-92.

Chandler, Alfred D. (1962), Strategy and Structure, 1990 ed., Cambridge: MIT Press.

Collis, David J. and Cynthia A. Montgomery (1995), 'Competing on Resources: Strategy in the 1990s', Harvard Business Review (July-August): 118-128.

Demsetz, Harold (1973), 'Industrial Structure, Market Rivalry, and Public Policy=, Journal of Law and Economics 16: 1-10.

Dierickx, Ingemar and Karel Cool (1989), "Asset Stock Accumulation and the Sustainability of Competitive Advantage”, Management Science 35: 1504-1511.

Foss, Nicolai J. (1996a), "Whither the Competence Perspective?”, in Nicolai J. Foss and Christian Knudsen, Towards a Competence Theory of the Firm, London: Routledge. 
Foss, Nicolai J. (1997), "Research in Strategy, Economics, and Michael Porter", Journal of Management Studies 33: 1-24.

Foss, Nicolai J. (1997), Resources and Strategy: A Reader, Oxford: Oxford University Press.

Foss, Nicolai J. and Bo Eriksen (1995), 'Industry Capabilities and Competitive Advantage', in Cynthia A. Montgomery, ed. (1995), Resource-Based and Evolutionary Theories of the Firm, Boston: Kluwer.

Foss, Nicolai J., Christian Knudsen, and Cynthia A. Montgomery (1995), 'An Exploration of Common Ground: Integrating Evolutionary and Strategic Theories of the Firm', in Cynthia A. Montgomery, ed. (1995), Resource-Based and Evolutionary Theories of the Firm, Boston: Kluwer.

Hofer, Charles and Dan Schendel (1979), Strategy Formulation: Analytical Concepts, St. Paul: West.

Hogarth, Robin M., Claude Michaud, Yves Doz and Ludo Van der Heyden (1991), 'Longevity of Business Firms: A Four-Stage Framework For Analysis', unpublished manuscript.

Huber, George P. (1991), 'Organizational Learning: The Contributing Processes and The Literatures,' Organization Science 2: 88-115.

Itami, Hiroyuki (1987), Mobilizing Invisible Assets, Harvard University Press, Cambridge, Mass.

Kay, John (1993), The Foundations of Corporate Success, Oxford University Press, Oxford.

Kirzner, Israel M. (1973), Competition and Entrepreneuship, Chicago: University of Chicago Press.

Lippman, Stephen A. and Richard P. Rumelt (1982), 'Uncertain Imitability: An Analysis of Interfirm Differences Under Competition', Bell Journal of Economics 13: 418-438.

Loasby, Brian J. (1976), Choice, Complexity, and Ignorance, Cambridge University Press, Cambridge.

Lucas, Robert E. (1978), 'On the Size Distribution of Business Firms', Bell Journal of Economics 9: $508-523$. 
Mahoney, Joseph T. (1995), 'The Management of Resources and the Resource of Management', Journal of Business Research 33: 91-101.

Marengo, Luigi (1992), 'Structure, Competence, and Learning in an Adaptive Model of the Firm,' Papers edited by the European Study Group for Evolutionary Economics, \#9203, Freiburg.

Markides, Constantinos C. \& Peter J. Williamson (1994): Related Diversification, Core Competences and Corporate Performance. Strategic Management Journal 15: 149-165.

Milgrom, Paul and John Roberts (1995), The Economics of Modern Manufacturing: Technology, Strategy and Organization', American Economic Review 80: 511-528.

Mintzberg, Henry (1990), 'Strategy Formation: Schools of Thought', in J.W. Fredrickson, ed. (1990), Perspectives on Strategic Management, New York: Harper.

Mintzberg, Henry (1994), The Decline and Fall of Strategic Planning, New York: Prentice-Hall.

Montgomery, Cynthia A. (1994), 'Corporate Diversification', Journal of Economic Perspectives 8: 163-178.

Montgomery, Cynthia A. (1995), 'Of Diamonds and Rust: A New Look at Resources', in idem., ed. (1995), Resource-Based and Evolutionary Theories of the Firm, Boston: Kluwer.

Montgomery, Cynthia A. and Birger Wernerfelt (1988), "Diversification, Ricardian Rents, and Tobin's q', RAND Journal of Economics 19: 623-622.

Mosakowski, Elaine and Bill McKelvey (1995), 'Bringing the Environment Into the ResourceBased View of Strategy', forthcoming in Aimé Heene and Ron Sanchez, eds. (1997), Competence-Based Strategic Management, Oxford: Elsevier.

Mahoney, Joseph T. and J. Rajendran Pandian (1992), "The Resource-Based View Within the Conversation of Strategic Management”, Strategic Management Journal 13: 363-380.

Nelson, Richard R. and Sidney G. Winter (1982), An Evolutionary Theory of Economic Change, Cambridge: The Belknap Press.

Penrose, Edith T. (1952), 'Biological Analogies in the Theory of the Firm', American Economic Review, 42, 804-819. 
Penrose, Edith T. (1959), The Theory of the Growth of the Firm, Oxford: Oxford University Press.

Peteraf, Margaret A. (1993), "The Cornerstones of Competitive Advantage: A Resource-Based View", Strategic Management Journal 14: 179-191.

Peters, Thomas J. and Robert H. Waterman (1982), In Search of Excellence, Harper \& Row, Cambridge, Mass.

Porter, Michael E. (1990), The Competitive Advantage of Nations, New York: Free Press.

Porter, Michael E. (1994), 'Toward a Dynamic Theory of Strategy', in Richard P. Rumelt, Dan E. Schendel, and David J. Teece, eds., Fundamental Issues in Strategy, Boston: Harvard Business School Press .

Prahalad, C.K. and Gary Hamel (1990) : The Core Competence of the Corporation. Harv ard Business Review 66 (May/June): 79-91.

Quinn, James Brian (1980), Strategies for Change: Logical Incrementalism, Homewood, Illinois: Irwin.

Rumelt, Richard P. (1984), "Towards a Strategic Theory of the Firm”, in Richard B. Lamb (ed.) (1984), Competitive Strategic Management, New Jersey: Englewood Cliffs.

Sanchez, Ron (1993), 'Strategic Flexibility, Firm Organization, and Managerial Work in Dynamic Markets: A Strategic Options Perspective', Advances in Strategic Management 9: 251-291.

Schoemaker, Paul and Raphael Amit (1994), 'Investment in Strategic Assets: Industry and FirmLevel Perspectives', Advances in Strategic Management 10: 3-33.

Schulze, William (1994), 'The Two Schools of Thought in Resource-Based Theory', Advances in Strategic Management 10: 127-152.

Selznick, Philip (1957), Leadership in Administration, Berkeley: Harper \& Row.

Spender, J.-C. (1992), 'Strategy Theorizing: Expanding the Agenda', Advances in Strategic Management, 8, 3-32.

Teece, David J. (1980), "Economies of Scope and the Scope of the Firm", Journal of Economic 
Behavior and Organization 1: 233-247.

Teece, David J., Gary Pisano and Amy Shuen (1995), "Dynamic Capabilities and Strategic Management", forthcoming in Strategic Management Journal 16.

Tirole, Jean (1988), The Theory of Industrial Organization, MIT Press, Cambridge, Mass.

Wernerfelt, Birger (1984), “A Resource-Based View of the Firm.” Strategic Management Journal 5: 171-180.

Wernerfelt, Birger (1995), 'Resource-Based Strategy in a Stochastic Model', in Cynthia A. Montgomery, ed. (1995), Resource-Based and Evolutionary Theories of the Firm, Boston: Kluwer.

Williams, Jeffrey A. (1992), 'How Sustainable is Your Competitive Advantage?', California Management Review 34: 29-51. 


\section{$\mathbf{D}_{\text {anish }} \mathbf{R}_{\text {esearch }} \mathbf{U}_{\text {nit for }} \mathbf{I}_{\text {ndustrial }} \mathbf{D}_{\text {ynamics }}$}

The Research Programme

The DRUID-research programme is organised in 3 different research themes :

\section{- The firm as a learning organisation}

- Competence building and inter-firm dynamics

- The learning economy and the competitiveness of systems of innovation

In each of the three areas there is one strategic theoretical and one central empirical and policy oriented orientation.

\section{Theme A: The firm as a learning organisation}

The theoretical perspective confronts and combines the ressource-based view (Penrose, 1959) with recent approaches where the focus is on learning and the dynamic capabilities of the firm (Dosi, Teece and Winter, 1992). The aim of this theoretical work is to develop an analytical understanding of the firm as a learning organisation.

The empirical and policy issues relate to the nexus technology, productivity, organisational change and human ressources. More insight in the dynamic interplay between these factors at the level of the firm is crucial to understand international differences in performance at the macro level in terms of economic growth and employment.

\section{Theme B: Competence building and inter-firm dynamics}

The theoretical perspective relates to the dynamics of the inter-firm division of labour and the formation of network relationships between firms. An attempt will be made to develop evolutionary models with Schumpeterian innovations as the motor driving a Marshallian evolution of the division of labour.

The empirical and policy issues relate the formation of knowledge-intensive regional and sectoral networks of firms to competitiveness and structural change. Data on the structure of production will be combined with indicators of knowledge and learning. IOmatrixes which include flows of knowledge and new technologies will be developed and supplemented by data from case-studies and questionnaires. 
Theme C: The learning economy and the competitiveness of systems of innovation.

The third theme aims at a stronger conceptual and theoretical base for new concepts such as 'systems of innovation' and 'the learning economy' and to link these concepts to the ecological dimension. The focus is on the interaction between institutional and technical change in a specified geographical space. An attempt will be made to synthesise theories of economic development emphasising the role of science based-sectors with those emphasising learning-by-producing and the growing knowledge-intensity of all economic activities.

The main empirical and policy issues are related to changes in the local dimensions of innovation and learning. What remains of the relative autonomy of national systems of innovation? Is there a tendency towards convergence or divergence in the specialisation in trade, production, innovation and in the knowledge base itself when we compare regions and nations?

\section{The Ph.D.-programme}

There are at present more than $10 \mathrm{Ph} . \mathrm{D}$.-students working in close connection to the DRUID research programme. DRUID organises regularly specific Ph.D-activities such as workshops, seminars and courses, often in a co-operation with other Danish or international institutes. Also important is the role of DRUID as an environment which stimulates the Ph.D.-students to become creative and effective. This involves several elements:

- access to the international network in the form of visiting fellows and visits at the sister institutions

- participation in research projects

- access to supervision of theses

- access to databases

Each year DRUID welcomes a limited number of foreign Ph.D.-students who wants to work on subjects and project close to the core of the DRUID-research programme.

\section{External projects}

DRUID-members are involved in projects with external support. One major project which covers several of the elements of the research programme is DISKO; a comparative analysis of the Danish Innovation System; and there are several projects involving international co-operation within EU's 4th Framework Programme. DRUID is open to host other projects as far as they fall within its research profile. Special attention is given to the communication of research results from such projects to a wide set of social actors and policy makers. 


\section{DRUID Working Papers}

96-1 Lundvall, Bengt-Åke: The Social Dimension of the Learning Economy. (ISBN 87-7873-000-7)

96-2 Foss, Nicolai J.: Firms, Incomplete Contracts and Organizational Learning. (ISBN 87-7873-001-5)

96-3 Dalum, Bent and Villumsen, Gert:Are OECD Export Specialisation Patterns 'Sticky?' Relations to the Convergence-Divergence Debate. (ISBN 87-7873-002-3)

96-4 Foss, Nicolai J: Austrian and Post-Marshallian Economics: The Bridging Work of George Richardson. (ISBN 87-7873-003-1)

96-5 Andersen, Esben S., Jensen, Anne K., Madsen, Lars and Jørgensen, Martin: The Nelson and Winter Models Revisited: Prototypes for Computer-Based Reconstruction of Schumpeterian Competition. (ISBN 87-7873-005-8)

96-6 Maskell, Peter: Learning in the village economy of Denmark. The role of institutions and policy in sustaining competitiveness. (ISBN 87-7873-006-6)

96-7 Foss, Nicolai J. \& Christensen, Jens Frøslev: A Process Approach to Corporate Coherence. (ISBN 87-7873-007-4)

96-8 Foss, Nicolai J.: Capabilities and the Theory of the Firm. (ISBN 87-7873-008-2)

96-9 Foss, Kirsten: A transaction cost perspective on the influence of standards on product development: Examples from the fruit and vegetable market. (ISBN 87-7873009-0)

96-10 Richardson, George B.: Competition, Innovation and Increasing Returns. (ISBN 877873-010-4)

96-11 Maskell, Peter: Localised low-tech learning in the furniture industry. (ISBN 87-7873-011-2)

96-12 Laursen, Keld: The Impact of Technological Opportunity on the Dynamics of Trade Performance. (ISBN 87-7873-012-0)

96-13 Andersen, Esben S.: The Evolution of an Industrial Sector with a Varying Degree of Roundaboutness of Production. (ISBN 87-7873-013-9)

96-14 Dalum, Bent, Laursen, Keld \& Villumsen, Gert: The Long Term Development of OECD Export Specialisation Patterns: De-specialisation and "Stickiness". (ISBN 877873-014-7)

96-15 Foss, Nicolai J.: Thorstein B. Veblen: Precursor of the Competence-Based Approach to the Firm. (ISBN 87-7873-015-5) 
96-16 Gjerding, Allan Næs: Organisational innovation in the Danish private business sector. (ISBN 87-7873-016-3)

96-17 Lund, Reinhard \& Gjerding, Allan Næs: The flexible company Innovation, work organisation and human ressource management. (ISBN 87-7873-017-1)

97-1 Foss, Nicolai J.: The Resource-Based Perspective: An Assessment and Diagnosis of Problems. (ISBN 87-7873-019-8)

\section{Information for subscribers.}

Subscription price for 1996 is 600 DKR (about 20 papers). The rate for single issues is 40 DKR. It is possible to make a commitment to an exchange of papers from related departments or research teams. All correspondence concerning the DRUID Working Papers should be send to:

Mette Madsen

Fibigerstræde 4, DK-9220 Aalborg OE

Tel. 45981542 11-2945

Fax. 4598156013

E-mail: mm@business.auc.dk 